\title{
¿COSMOPOLITISMO O ACULTURACIÓN? LOS PRINCIPIOS Y DERECHOS FUNDAMENTALES DE LA CONSTITUCIÓN POLÍTICA DE COLOMBIA DE 1991*
}

\section{COSMOPOLITANISM OR ACCULTURATION? THE PRINCIPLES AND FUNDAMENTAL RIGHTS OF THE COLOMBIAN POLITICAL CONSTITUTION OF 1991}

\author{
Luis Fernando Bustamante-Zapata**
}

\section{Resumen}

Objetivo. Este artículo analiza las posibles influencias sobre la Constitución Política de Colombia de 1991 y prepara el terreno para un debate de las consecuencias por efectos de aculturación. Metodología. Siguiendo el método analítico se descomponen los principios y derechos fundamentales en la Constitución para identificar los ideales que la fundan. Resultados. Se observa que los principios y derechos fundamentales promulgados en la Carta Magna de 1991 dan cuenta de ideales cosmopolitas. Además, aparece un posible fenómeno de aculturación sobre una sociedad que necesitaba rumbo y misión. Conclusión. La formación de la República de Colombia fue un complejo proceso para la institucionalización de estructuras de poder bajo ideales que garantizaran la cohesión del territorio plasmadas en un documento fundacional denominado Constitución.

Palabras clave: cosmopolitismo, aculturación, sociología del conocimiento.

\begin{abstract}
Objective. This article analyzes the possible influences on the 1991 Political Constitution of Colombia and paves the way for a debate on the consequences of acculturation. Methodology. Following the analytical method, the principles and fundamental rights in the Constitution are broken down to identify the ideals that found them. Results. It is noted that the principles and fundamental rights promulgated in the 1991 Magna Carta account for cosmopolitan ideals. In addition, a possible phenomenon of acculturation appears on a society that needed direction and mission. Conclusion. The formation of the Republic of Colombia was a complex process for the institutionalization of power structures under ideals that would guarantee the cohesion of the territory embodied in a foundational document called the Constitution.
\end{abstract}

Key words: cosmopolitanism, acculturation, sociology of knowledge.

\footnotetext{
* Este artículo de reflexión, derivado de investigación, fue producto del trabajo de grado del autor para optar al grado de Doctor en Humanidades titulado: Análisis de las perspectivas cosmopolitas sobre la interculturalidad: UNAOC y las alternativas hacia la comprensión de las dificultades para la convivencia global.

${ }^{* *}$ Universidad EAFIT. Medellín, Colombia. E-mail: lbustam3@eafit.edu.co -

(D) orcid.org/0000-0002-0504-1819. Google Scholar
} 


\section{Introducción}

Tal vez el mundo nunca fue tan chico y a la vez tan infranqueable como lo es hoy. El avance de las tecnologías de información y comunicación, en conjunto con los negocios globales y otros movimientos socioculturales, han puesto a la humanidad al borde de un abismo insalvable al cual jamás se había enfrentado de la manera en que ahora se presenta: su enorme diversidad ${ }^{1}$. Ante este nuevo 'pluriverso', la posibilidad de grandes conflictos, enmarcados por primera vez en la eventualidad de una destrucción de proporciones globales, y el progreso de corrientes de pensamiento que se adentran en los asuntos de los diferentes pueblos, parece cobrar valor con el retorno de los nacionalismos.

El pensamiento es víctima de la reducción virtual del espacio, la ampliación de las posibilidades y los riesgos. Encuentra limitado su alcance cuando atraviesa diferentes visiones del hombre y se enfrenta a la diversidad humana de territorio en territorio. Giddens, Bauman, Luhmann y Beck (1996) se refieren a esta suerte de paradoja como una consecuencia perversa de la modernidad. En adición, los estudios de Weber (2003) indican que la influencia de la diversidad tiene efectos positivos o negativos en la vida de los pueblos por causa de ideologías ${ }^{2}$ que cruzan desde el imaginario colectivo hacia construcciones sociales alimentadas por costumbres y normas globalmente diseminadas. En especial, podemos identificar que el pensamiento más diseminado en el mundo es aquel conocido como moderno, y después posmoderno, caracterizado por movimientos de carácter humanista y ecológicos.

Precisamente para Colombia la introducción del pensamiento moderno representa un renacimiento 'a la chibcha', por así decirlo ${ }^{3}$. De la misma manera que el territorio nacional sufrió en primera fila las atrocidades de los regímenes coloniales cuando estos llegaron al continente, es ahora castigado con la introducción de ideas europeas desde mitades del siglo XX. Castigado porque, con la intención de aliviar cualquier rezago, alcanzar a las potencias mundiales, alimentar las mentes inquietas y superar los problemas del desarrollo, las ideas

\footnotetext{
${ }^{1}$ Según Todorov (1991), la diversidad, como concepto, abarca dos problemas fundamentales: las infinitas diferencias entre los grupos humanos, por un lado; y la universalización de los juicios y valores, por el otro. A esto, el autor lo concibe como el problema de lo relativo y lo universal. Sin embargo, definir diversidad es constreñir el significado de esta palabra en la realidad, puesto que la diversidad humana es infinita, y definir es en sí, proporcionar un final a una idea. Buscando un balance, en este texto nos podemos referir como diversidad a lo que tradicionalmente se conoce como diversidad cultural, muy bien ilustrada por Geertz (1996) en su obra Los usos de la diversidad, por Olivé (2004) en Ética y diversidad cultural o el mismo Todorov (1991), ya citado en su obra Nosotros y los otros: reflexión sobre la diversidad humana.

${ }^{2}$ Eagleton (1991) agrupa las definiciones de ideología en seis conjuntos: 1. El proceso general de producción de ideas, 2. Ideas o creencias de un grupo o clase de personas representativo, 3. Un discurso orientado a la promoción y legitimación de intereses de grupos, 4. Un discurso de grupos dominantes que busca unificar una formación social, 5. Ideas y creencias que legitiman los intereses de un grupo o clase gobernante y 6 . Creencias que surgen de la estructura material de una sociedad como un todo.

${ }^{3}$ Martínez (2001) ofrece un interesante y revelador análisis de cómo los principios nacionalistas europeos permearon la construcción del Estado colombiano. Si bien su estudio reduce el cosmopolitismo al liberalismo hegemónico, también da cuenta de cómo las ideas viajaron a través del Atlántico para inspirar a los próceres de la patria.
} 
entran a instigar inoportunos - o inefectivos- cambios sociales sin el suficiente entendimiento de los problemas locales (Martínez, 2001). En apariencia, los impulsores del desarrollo en otras latitudes, como es fácilmente comprobable en los indicadores socioeconómicos de Colombia, no surtieron el mismo efecto y en cambio podríamos argumentar acerca de un proceso de aculturación que no necesariamente fue benéfico para el país, puesto que nuestras realidades fueron violentadas.

Aunque otros hechos político-sociales aparte de la introducción del pensamiento moderno pueden ser resaltados como hitos en la historia nacional, tal vez la promulgación de la Constitución Política de Colombia de 1991, después de un siglo de haberse decretado la Carta Magna de 1886, representa la clara aceptación de las ideas del pensamiento posmoderno por parte de la sociedad. Este texto renueva, oxigena y reforma grandes estancias sociales, políticas y jurídicas que daban estructura a la nación colombiana. Sin embargo, la misma historia de Colombia demuestra que las transformaciones en los sistemas de poder derivan constantemente en serios conflictos. Las raíces de estas transformaciones son clave para comprender los porqués del país.

Este documento tiene como objetivo elevar un debate alrededor de los derechos y principios fundamentales de la Constitución Política de Colombia de 1991 contrastando desde el cosmopolitismo la posibilidad de un proceso de aculturación. Por tanto, en el texto se pretende debatir nuevos porqués. En primer lugar, se tiene como propósito definir aquello que se denomina cosmopolitismo y aquello denominado aculturación. Luego, presenta un recorrido con los aportes principales de las constituciones colombianas desde 1886. Más adelante, se concentra especialmente en los derechos y principios fundamentales de la Constitución Política de 1991, para enseñar los ideales cosmopolitas que penetraron en el texto. Entonces, presenta una reflexión sobre las consecuencias de estas decisiones en tanto pueden ser interpretadas como procesos de aculturación. Así se espera poner de manifiesto algunos procesos globales que desembocaron en transformaciones de los sistemas de poder colombianos para futuros caminos de investigación. 


\section{Discusión}

\section{Cosmopolitismo: el triunfo del liberalismo y el retiro del Estado}

En nuestra era definir -y defender- un cosmopolitismo implica profundizar en muchas disciplinas del saber ${ }^{4}$. Por ende, traeremos elementos de la filosofía moral, la política y la sociología que luego servirán para resaltar en la Constitución Política de 1991 diferentes aspectos que nos competen. Se habla de cosmopolitismo con referencia a aquellos proyectos cuyo objetivo reside en la convivencia global y su ideología enmarca aspectos políticos, morales, económicos, entre otros, que facilitan la coexistencia ante un mundo diverso en condiciones de bienestar (Beck, 2006). En palabras de Mignolo (2000), el cosmopolitismo es "un conjunto de proyectos dirigidos a la convivencia planetaria” (p. 721). Al agrupar diferentes proyectos, el cosmopolitismo tiene aspiraciones universales y es resultado de la suma de múltiples conceptos que lo hacen difícil de abordar: globalización, ciudadanía global, medio ambiente, paz mundial, supranacionalidad, entre otros, que agrandan dicha dificultad.

Como otras ideas, el cosmopolitismo no necesariamente representa un consenso de todos los habitantes del planeta sino el triunfo de unos conceptos sobre otros, o de unos pueblos sobre otros, por diferentes razones. Sin embargo, nos interesan sobremanera las razones socioeconómicas que permiten la coexistencia, dentro de marcos normativos que maticen la asimetría de las relaciones humanas. Se hace necesario un llamado al establecimiento de sistemas que permitan que la soberanía estatal, completamente transformada, se articule a favor de múltiples identidades interdependientes. Empero, estos sistemas o marcos normativos nos presentan en su interior una dificultad: "Están siempre marcados culturalmente" (Reder, 2012, p. 35). Dicha marca entorpece la tarea cosmopolita de mantener la coexistencia dentro de parámetros racionales de bienestar.

El triunfo de un sistema o marco normativo sobre otro puede ser tan beneficioso como contraproducente dependiendo de muchos factores. Ejemplo: si hacemos una analogía entre la toma de tierra por mecanismos de guerra como planteaba Schmitt (2002) con una toma de tierra por mecanismos ideológicos, compartiendo la visión de Mannheim (2004) acerca del concepto 'ideología', podemos concluir que los últimos son procesos sociales con alto potencial de conflicto. Si las ideologías están asociadas con actores en disputa por dominio territorial,

\footnotetext{
${ }^{4}$ Hablar de cosmopolitismo, como indica Toulmin (1992), supone un acercamiento al cosmos ( $\left.\kappa o ́ \sigma \mu o \varsigma\right)$, a sus elementos compositivos, y a las relaciones entre ellos que buscan oponerse al caos $(\chi \alpha ́ o \sigma)$ en la estructura amplia de las sociedades cuyos individuos serían denominados cosmopolitas (kosmopolitês). Debido a lo anterior, en los documentos que trabajan el cosmopolitismo no es extraño observar el uso copioso de conceptos entrelazados, eso sí, buscando precisamente deliberar metodológicamente con ellos, para conseguir resemantizarlos en algunos casos. El cosmopolitismo es de por sí un fenómeno trascendental, que supeditado al sujeto que lo estudia, toma forma (Kant, 1998). Quien investiga sobre cosmopolitismo no solo corre el riesgo de abordar múltiples temáticas y conceptos, sino que, además, por la naturaleza del fenómeno, debe hacerlo, guardando los criterios de rigor que la ciencia merece.
} 
la probabilidad de conflicto se multiplica. Según Baumann (2001), en cada territorio existen grupos humanos que exigen derechos cívicos, comunitarios o religiosos según sea su interés por motivos de cultura nacional, identidad étnica o religión. La relativa paz entre estos grupos se logró por medio de un contrato social en el cual, de forma cuestionable, se limitó al Estado a ser simplemente servidor del bien común y se le confundió como el Gobierno en general. En general, bajo un panorama de diversidad de derechos civiles, culturales y religiosos, "no hay forma de resolver el enigma multicultural si eludimos la cuestión de las diferencias y tratamos a un tipo de derechos como si fuera 'básicamente el mismo' que los otros dos” (Baumann, 2001, p. 23).

Con la comprensión de la diversidad, no todos los pensamientos globales son cosmopolitas ya que para serlo deben respetar los variados tipos de sociedades y promover la tolerancia, solidaridad, justicia y libertad como punta de lanza de su proyecto ideológico. Es decir, la cuestión de las diferencias es de gran importancia dado que uno de los principales objetivos del cosmopolitismo radica en la transferencia de valores que tienen cuna en Occidente y aunque existen en otros hemisferios, son concebidos de diferente manera. Dichos valores son producto de construcciones sociales y culturales que posteriormente fundan las bases de los sistemas políticos con el propósito de garantizar la paz en un Estado. Los sistemas jurídicos, como las cartas fundacionales de los países, es decir, las constituciones políticas tienen un fuerte fundamento en valores.

Resulta brusca la transición entres cosmopolitismo y valores, pero también resulta justificada porque con la excusa de legislar para garantizar estas bases fundacionales, los gobiernos pueden cometer atropellos contra minorías y grupos de oposición que quedan excluidos de los proyectos nacionales. Por ende, con el desprendimiento del pensamiento político excesivamente racionalista, "la aspiración del cosmopolita es respetar las diferencias y, al mismo tiempo, conservar el universalismo ético" (Reder, 2012, p. 221). Luego, el problema del cosmopolitismo es axiológico además de moral, ya que implica revisar las más profundas fundaciones del ser humano.

Redondeando, el cosmopolitismo implica el triunfo de una ideología que se expandió y está siendo aceptada alrededor del mundo en el marco de una ciudadanía global, que abarca todas las esferas del desarrollo humano (Cortina, 2005a). Escribir una historia de la idea (Brinton, 1979), implicaría recorrer los pensamientos que en algún momento fueron globales, listar los diferentes autores, describirlos en contexto y analizar las causas de su auge y declive. Sin duda alguna, esto no es menos que un tratado para el cual no hay suficiente espacio, pero podemos listarlos rápidamente a continuación ${ }^{5}$.

\footnotetext{
${ }^{5}$ Para el lector aclaro que la historia que presento aquí es básicamente la que se ha escrito, es decir, no necesariamente advierte todas las manifestaciones de pensamiento en el mundo entre las cuales se observan caracteres globales o cosmopolitas.
} 
Posiblemente el primer pensamiento global reconocido en los anales de la historia es el pensamiento greco-romano, representado por los sofistas, Sócrates, Platón, Aristóteles, entre $\operatorname{otros}^{6}$, quienes fundaron un proyecto ético, político y social basado en la virtud ciudadana que dominó el hemisferio occidental hasta la caída del Imperio Romano. Luego, el ascenso del cristianismo como doctrina imperial, fundado en una idea monoteísta, dictó los caminos del hombre con base en la solidaridad, fraternidad y hermandad cristiana, y por supuesto, en la obediencia absoluta a las normas divinas. Más adelante, el pensamiento europeo imperial, absolutamente racionalista, positivista, liberal, representado en las ideas de Hegel, Kant, Rousseau, Nietzsche, Arendt, entre otros, que dominó hasta mitad del siglo XX conformó otro pensamiento global. Ahora el pensamiento global está en parte representado por el movimiento liberal de la globalización representado en autores como Rawls, Höffe, Walzer, Rorty y otros, dedicados a problemas relativos a la justicia, la libertad, el patrimonio cultural y la conservación de la tierra. El siglo XXI es otro asunto completamente diferente y aún por resolver; parece haber un llamado a un pensamiento de la virtud global, todavía por describir (Reder, 2012).

El recorrido anterior nos demuestra que las ideas globalmente difundidas no necesariamente son cosmopolitas -algunos pensamientos globales son etnocentristas o imperialistas-, pero tienen como característica principal que transfieren importantes ideas y, hoy han convergido en ciertos acuerdos mínimos para la convivencia de los pueblos. El problema en realidad no radica en definir qué es cosmopolita y qué no lo es, sino en comprender qué significa cosmópolis, y por encima de esto, en discernir qué elementos de la cultura y la vida en sociedad le dan forma ${ }^{7}$. En otras palabras, quizás es de mayor importancia preguntarse: ¿cómo interpretan los valores los diferentes grupos humanos?, ¿qué posibilidades existen de que nuestra concepción de valor atente contra otras construcciones axiológicas?, y ¿cómo sería un valor universal e intercultural en contraposición a uno particular y etnocentrista? De nuevo, nos topamos con una problemática para la cual siglos han transcurrido sin llegar a una solución convincente. No obstante, la diversidad no ha sido impedimento para la conformación de estructuras sociopolíticas de agrupación que comparten ciertos principios éticos.

\section{Un país que se construye en su ley}

Ante la inmensa diversidad de la humanidad, "es imposible un consenso ético total" (Kung, 1999, p. 113), razón por la cual hay que buscar un mínimo consenso ético que permita la conformación de estructuras sociopolíticas. De esta manera se refundó la República de

\footnotetext{
${ }^{6}$ Cómo olvidar a Diógenes el Cínico, quien cuestionara la moral y política de su época, y por medio del desahucio, podría calificarse como el primer cosmopolita.

${ }^{7}$ Bustamante (2015) afirma que, como muchas ideas y conceptos, el cosmopolitismo cambia y toma forma gracias a los acontecimientos de la actualidad. No obstante, se requiere profundizar en la estructura metodológica que funde un espíritu cosmopolita de acuerdo con las barreras insalvables de los gustos y la cultura.
} 
Colombia en 1991, por medio de la promulgación de una nueva Carta Magna, más de un siglo después de haber sido escrita la última. Esto, por supuesto, no fue un proceso aislado. Fue producto de una serie de cambios socioculturales impulsados por elementos económicos, pero, sobre todo, por la introducción de las ideas del pensamiento moderno en Colombia; un pensamiento que se difundía rápidamente alrededor del globo para la época. Sin embargo, ¿fue esta Constitución la respuesta a los retos que enfrentaba el país? ¿Se logró un marco incluyente que representara a las comunidades multiculturales de todas las latitudes del país?Y, ¿qué efectos socioculturales y económicos generó este cambio?

Es posible afirmar que el desarrollo sociocultural de Colombia tiene base precisa en las reformas de 1850 que rompieron con la marcada tradición colonial.

El comercio exterior, con el tabaco a la cabeza, barrió con las economías
de archipiélago, retraídas e incomunicadas de la colonia y creó las
condiciones para la formación de una economía nacional basada en
vínculos estables entre los sectores productivos del territorio de
Colombia. (Cataño, 2012, p. 209)

Las medidas implementadas entonces, junto con otras fuerzas de la globalización, permitieron la entrada del pensamiento moderno en el país. Además, dieron origen al cambio de la nación federal que éramos, a la nación republicana que somos hoy, materializado en la promulgación de la Constitución de 1886. Más adelante, en el siglo XX, las guerras mundiales y el conflicto armado con Perú obligaron al Estado a acelerar la implementación de diversos cambios con el motivo de igualarse con el ambiente internacional. Adicional a esto, la revolución educativa de finales de los años 60 permitió la discusión acalorada de la necesidad inminente de darle nuevo sentido a la sociedad plural, multiétnica y necesitada de políticas económicas y sociales orientadas al desarrollo (Cataño, 2005).

En realidad, la historia de la Audiencia y Cancillería Real de Santafé (bajo la jurisdicción del Virreinato del Perú), luego delVirreinato de la Nueva Granada, la Gran Colombia, la República de la Nueva Granada, la Confederación Granadina, los Estados Unidos de Colombia y hoy, la República de Colombia, está marcada por la búsqueda de institucionalizar un Estado que cobije la multiplicidad étnica presente en el territorio y a la vez evite la lucha regionalizada por el poder. También fue ejemplo de cómo el auge o dominio de un grupo humano -criollo, chapetón, mestizo o indígena-, buscó reafirmar identidades mediante mecanismos formales de gobierno y, por ende, de Estado. La sucesión interminable de conflictos (más de 40 se cuentan durante el periodo federal del país), reafirma el enigma multicultural que Baumann (2001) planteó alrededor de la nación, la religión y las etnias, presentes en el territorio colombiano y aún en apuros por diferentes motivos. 
A finales del siglo XX, las grandes disputas de antaño y los nuevos problemas del país conllevaron a una Asamblea Nacional Constituyente en 1991 que pretendía subsanar los diferentes atropellos que el sistema bipartidista, principalmente, había cometido contra las minorías en el país, sea por acción u omisión. Ocampo (2004), demuestra en sus estudios la inestabilidad de cada periodo estatal en Colombia y cómo cada toma de tierra se institucionalizó con una nueva Carta Magna. De acuerdo con el estudio histórico presentado por dicho autor y el repositorio digital de constituciones disponible en la Universidad Nacional y el Banco de la República, podemos conformar la siguiente tabla que nos habla de los aportes principales de las constituciones políticas promulgadas en la historia de Colombia ${ }^{8}$ :

Tabla 1. Las constituciones políticas promulgadas en el territorio colombiano

\begin{tabular}{|c|c|c|c|c|c|}
\hline \# & Período & Nombre & Autor & Fecha & Aporte principal \\
\hline 1 & Pos-conquista & $\begin{array}{l}\text { Acta de la } \\
\text { Revolución }\end{array}$ & $\begin{array}{l}\text { Ejército } \\
\text { Republicano } \\
\text { Patriota }\end{array}$ & $\begin{array}{l}20 \text { de julio } \\
\text { de } 1810\end{array}$ & $\begin{array}{l}\text { Se entrega el poder a } \\
\text { la Junta Suprema de } \\
\text { Gobierno }\end{array}$ \\
\hline 2 & Patria Boba & $\begin{array}{l}\text { Constitución } \\
\text { de } \\
\text { Cundinamarca }\end{array}$ & $\begin{array}{l}\text { Provincia de } \\
\text { Cundinamarca }\end{array}$ & $\begin{array}{l}30 \text { de } \\
\text { marzo de } \\
1811\end{array}$ & $\begin{array}{l}\text { Carácter monárquico- } \\
\text { republicano }\end{array}$ \\
\hline 3 & Patria Boba & $\begin{array}{l}\text { Acta de la } \\
\text { Federación de } \\
\text { las Provincias } \\
\text { Unidas de la } \\
\text { Nueva Granada }\end{array}$ & $\begin{array}{l}\text { Federación de } \\
\text { las Provincias } \\
\text { Unidas de la } \\
\text { Nueva Granada }\end{array}$ & $\begin{array}{l}27 \text { de } \\
\text { noviembre } \\
\text { de } 1811\end{array}$ & $\begin{array}{l}\text { Liderada por el payanés } \\
\text { Camilo Torres, era de } \\
\text { carácter federalista }\end{array}$ \\
\hline
\end{tabular}

\footnotetext{
${ }^{8}$ A propósito, el repositorio digital de la Universidad Nacional de Colombia es una fantástica herramienta para acceder a los textos de cada Constitución. Existen algunas diferencias entre las convenciones, congresos o asambleas que redactan las constituciones y la promulgación efectiva del documento. Por ejemplo, lo podemos ver en la Ley fundamental de la República de Colombia, redactada en el Congreso de Angostura del 17 de diciembre de 1819 pero publicada el 10 de febrero de 1820.
} 


\begin{tabular}{|c|c|c|c|c|c|}
\hline 4 & Patria Boba & $\begin{array}{l}\text { Constitución } \\
\text { de la República } \\
\text { de Tunja }\end{array}$ & $\begin{array}{l}\text { Asamblea de los } \\
\text { representantes } \\
\text { de la provincia }\end{array}$ & $\begin{array}{l}9 \text { de } \\
\text { diciembre } \\
\text { de } 1811\end{array}$ & \multirow{5}{*}{$\begin{array}{l}\text { Al igual que las } \\
\text { demás constituciones } \\
\text { de la Patria Boba, } \\
\text { buscaba emancipar un } \\
\text { territorio a favor de } \\
\text { un caudillo local o un } \\
\text { grupo político local }\end{array}$} \\
\hline 5 & Patria Boba & $\begin{array}{l}\text { Constitución } \\
\text { del Estado de } \\
\text { Antioquia }\end{array}$ & $\begin{array}{l}\text { Representantes } \\
\text { de la provincia }\end{array}$ & $\begin{array}{l}21 \mathrm{de} \\
\text { marzo de } \\
1812\end{array}$ & \\
\hline 6 & Patria Boba & $\begin{array}{l}\text { Constitución } \\
\text { del Estado } \\
\text { soberano de } \\
\text { Cartagena de } \\
\text { Indias }\end{array}$ & $\begin{array}{l}\text { Serenísima } \\
\text { Convención } \\
\text { general }\end{array}$ & $\begin{array}{l}14 \text { de junio } \\
\text { de } 1812\end{array}$ & \\
\hline 7 & Patria Boba & $\begin{array}{l}\text { Constitución } \\
\text { de Mariquita }\end{array}$ & $\begin{array}{l}\text { Convención } \\
\text { constituyente } \\
\text { y electoral } \\
\text { del Estado de } \\
\text { Mariquita }\end{array}$ & $\begin{array}{l}21 \text { de junio } \\
\text { de } 1815\end{array}$ & \\
\hline 8 & Patria Boba & $\begin{array}{l}\text { Constitución } \\
\text { de Neiva }\end{array}$ & $\begin{array}{l}\text { Convención } \\
\text { General de los } \\
\text { Representantes } \\
\text { del Estado libre } \\
\text { de Neiva }\end{array}$ & $\begin{array}{l}31 \text { de } \\
\text { agosto de } \\
1815\end{array}$ & \\
\hline 9 & $\begin{array}{l}\text { La Gran } \\
\text { Colombia }\end{array}$ & $\begin{array}{l}\text { Ley } \\
\text { fundamental de } \\
\text { la República de } \\
\text { Colombia }\end{array}$ & $\begin{array}{l}\text { Soberano } \\
\text { Congreso de } \\
\text { Venezuela en } \\
\text { Angostura }\end{array}$ & $\begin{array}{l}17 \text { de } \\
\text { diciembre } \\
\text { de } 1819\end{array}$ & $\begin{array}{l}\text { Venezuela, } \\
\text { Cundinamarca y Quito } \\
\text { conformaron la Gran } \\
\text { Colombia }\end{array}$ \\
\hline 10 & $\begin{array}{l}\text { La Gran } \\
\text { Colombia }\end{array}$ & $\begin{array}{l}\text { Constitución } \\
\text { de Cúcuta }\end{array}$ & $\begin{array}{l}\text { Representantes } \\
\text { de los pueblos } \\
\text { de la Nueva } \\
\text { Granada y } \\
\text { Venezuela } \\
\text { reunidos en } \\
\text { Congreso } \\
\text { general }\end{array}$ & $\begin{array}{l}8 \text { de } \\
\text { octubre de } \\
1821\end{array}$ & $\begin{array}{l}\text { Reestructuró los } \\
\text { poderes públicos y } \\
\text { reafirmó la unión de } \\
\text { los pueblos de la Gran } \\
\text { Colombia }\end{array}$ \\
\hline
\end{tabular}




\begin{tabular}{|c|c|c|c|c|c|}
\hline 11 & $\begin{array}{l}\text { La Gran } \\
\text { Colombia }\end{array}$ & $\begin{array}{l}\text { Constitución } \\
\text { de } 1830\end{array}$ & $\begin{array}{l}\text { Congreso } \\
\text { Admirable }\end{array}$ & $\begin{array}{l}5 \text { de mayo } \\
\text { de } 1830\end{array}$ & $\begin{array}{l}\text { Estableció un } \\
\text { centralismo limitado, } \\
\text { precursor de la } \\
\text { desintegración de la } \\
\text { Gran Colombia }\end{array}$ \\
\hline
\end{tabular}

\begin{tabular}{|c|c|c|c|c|c|}
\hline 12 & $\begin{array}{l}\text { República } \\
\text { de la Nueva } \\
\text { Granada }\end{array}$ & $\begin{array}{l}\text { Constitución } \\
\text { Política de la } \\
\text { Nueva Granada }\end{array}$ & $\begin{array}{l}\text { Los } \\
\text { representantes } \\
\text { de la Nueva } \\
\text { Granada } \\
\text { reunidos en } \\
\text { Convención }\end{array}$ & $\begin{array}{l}7 \text { de marzo } \\
\text { de } 1832\end{array}$ & $\begin{array}{l}\text { Estableció un régimen } \\
\text { centralista }\end{array}$ \\
\hline
\end{tabular}

\begin{tabular}{|c|c|c|c|c|c|}
\hline \multirow{3}{*}{13} & & & Senado y & & \\
\hline & $\begin{array}{l}\text { República } \\
\text { de la Nueva } \\
\text { Granada }\end{array}$ & $\begin{array}{l}\text { Constitución } \\
\text { Política de } \\
1843\end{array}$ & $\begin{array}{l}\text { Cámara de } \\
\text { Representantes } \\
\text { de la Nueva }\end{array}$ & $\begin{array}{l}8 \text { de mayo } \\
\text { de } 1843\end{array}$ & $\begin{array}{l}\text { Régimen autoritario } \\
\text { conservador, religioso } \\
\text { de carácter católico }\end{array}$ \\
\hline & & & Granada & & \\
\hline
\end{tabular}

\begin{tabular}{|c|c|c|c|c|c|}
\hline 14 & $\begin{array}{l}\text { República } \\
\text { de la Nueva } \\
\text { Granada }\end{array}$ & $\begin{array}{l}\text { Constitución } \\
\text { Política de la } \\
\text { Nueva Granada } \\
\text { de } 1853\end{array}$ & $\begin{array}{l}\text { Senado y } \\
\text { Cámara de } \\
\text { Representantes } \\
\text { de la Nueva } \\
\text { Granada }\end{array}$ & $\begin{array}{l}20 \text { de mayo } \\
\text { de } 1853\end{array}$ & $\begin{array}{l}\text { Abolió la esclavitud, } \\
\text { fijó un régimen centro- } \\
\text { federal, promulgó } \\
\text { libertad religiosa, } \\
\text { de pensamiento, y la } \\
\text { posibilidad de cada } \\
\text { estado de redactar su } \\
\text { propia Constitución }\end{array}$ \\
\hline 15 & $\begin{array}{l}\text { Confederación } \\
\text { Granadina }\end{array}$ & $\begin{array}{l}\text { Constitución } \\
\text { Política para la } \\
\text { Confederación } \\
\text { Granadina de } \\
1858\end{array}$ & $\begin{array}{l}\text { Senado y } \\
\text { Cámara de } \\
\text { Representantes } \\
\text { de la Nueva } \\
\text { Granada }\end{array}$ & $\begin{array}{l}23 \text { de mayo } \\
\text { de } 1858\end{array}$ & $\begin{array}{l}\text { Denominó } \\
\text { Confederación } \\
\text { Granadina a la nación } \\
\text { soberana. Reafirmó } \\
\text { el sistema federal, los } \\
\text { derechos individuales, } \\
\text { libertad de prensa y } \\
\text { la separación entre el } \\
\text { Estado y la Iglesia, se } \\
\text { garantizó la libertad de } \\
\text { cultos y pensamientos. }\end{array}$ \\
\hline
\end{tabular}




\begin{tabular}{|c|c|c|c|c|c|}
\hline 16 & $\begin{array}{l}\text { Estados } \\
\text { Unidos de } \\
\text { Colombia }\end{array}$ & $\begin{array}{l}\text { Constitución } \\
\text { Política de } \\
1863\end{array}$ & $\begin{array}{l}\text { Convención } \\
\text { Nacional }\end{array}$ & $\begin{array}{l}8 \text { de mayo } \\
\text { de } 1863\end{array}$ & $\begin{array}{l}\text { Conformó los Estados } \\
\text { Unidos de Colombia, } \\
\text { fortaleció el Congreso } \\
\text { en detrimento del } \\
\text { poder ejecutivo, era } \\
\text { de marcado carácter } \\
\text { liberal, abolió la pena } \\
\text { de muerte, entregó } \\
\text { exagerado poder a los } \\
\text { estados federados }\end{array}$ \\
\hline 17 & $\begin{array}{l}\text { República de } \\
\text { Colombia }\end{array}$ & $\begin{array}{l}\text { Constitución } \\
\text { Política de } \\
1886\end{array}$ & $\begin{array}{l}\text { Delegatarios } \\
\text { de los Estados } \\
\text { Colombianos }\end{array}$ & $\begin{array}{l}5 \text { de agosto } \\
\text { de } 1886\end{array}$ & $\begin{array}{l}\text { Cambió el nombre } \\
\text { a República de } \\
\text { Colombia, separó los } \\
\text { poderes públicos en } \\
\text { ejecutivo, legislativo } \\
\text { y judicial con } \\
\text { marcada tendencia } \\
\text { presidencialista, } \\
\text { reconoció el } \\
\text { catolicismo como la } \\
\text { religión estatal. Fue } \\
\text { reformada en 1910, } \\
\text { 1936, 1945, 1957 y } \\
\text { 1968. }\end{array}$ \\
\hline 18 & $\begin{array}{l}\text { República de } \\
\text { Colombia }\end{array}$ & $\begin{array}{l}\text { Constitución } \\
\text { Política de } \\
1991\end{array}$ & $\begin{array}{l}\text { Asamblea } \\
\text { Nacional } \\
\text { Constituyente }\end{array}$ & $\begin{array}{l}4 \text { de julio } \\
\text { de } 1991\end{array}$ & $\begin{array}{l}\text { Estableció el Estado } \\
\text { social de derecho, es } \\
\text { rica en protección de } \\
\text { los derechos humanos, } \\
\text { la familia, la mujer, } \\
\text { los niños y demás } \\
\text { minorías en estado de } \\
\text { indefensión, debilitó } \\
\text { el poder ejecutivo y } \\
\text { fortaleció el judicial, } \\
\text { forjó garantías para } \\
\text { el multipartidismo, } \\
\text { incrementó los } \\
\text { mecanismos de } \\
\text { participación } \\
\text { democrática }\end{array}$ \\
\hline
\end{tabular}

Fuente: elaboración propia. 
En semejante revuelta constitucionalista del siglo XIX como enseña la Tabla anterior, ¿dónde quedaron los derechos, deberes e identidad de las minorías?, ¿la disputa constante por el territorio, natural a los procesos de conformación de los estados, había limitado el ingreso de ideas cosmopolitas? O, ¿fueron estas revueltas las que facilitaron la entrada de dichos pensamientos de carácter global? En cualquier caso, los eventos suscitados por las luchas imperiales en Europa nos facilitaron la tarea de promulgar nuestra independencia y de buscar, alrededor del mundo, las guías que fortalecieran nuestra nación. Entre estas guías las ideas cosmopolitas tuvieron entrada al país y son evidentes en la Constitución de 1991.

\section{Cosmopolitismo en Colombia: entre liberalismo y democracia}

La Asamblea Nacional Constituyente de 1991 fue un ejercicio democrático de representación en el cual se buscaba subsanar las debilidades del Estado colombiano. Por encima de eso, puede interpretarse como la reafirmación de un pueblo bajo las condiciones radicalmente diferentes que el siglo XX definió y el siglo XXI prometía. Pero ¿qué mecanismos, ideas o nociones de cosmopolitismo alimentaron la Constitución de 1991? ¿Qué valores, comportamientos y costumbres fueron codificados en la Carta Magna? Para el debate de estas dudas, es posible sentar un punto de partida en Rorty (1991), cuando anuncia que "debiéramos renunciar al intento de combinar la creación de sí mismo y la política, especialmente si somos liberales” (p. 139). Con esto en mente, se puede afirmar que, aunque muchas ideas importadas fortalecieron el ejercicio democrático constitucional, aún quedaba por delante la necesidad de formar una identidad nacional. De manera cuestionable tratamos por mucho tiempo de crear nuestra propia imagen e identidad a partir de manifestaciones políticas.

Dejando de lado el problema de la identidad y suponiendo que el cosmopolitismo satisfacía los intereses del Estado en reforma, o por lo menos de la Asamblea Nacional Constituyente, es posible identificar aspectos clave de cosmopolitismo en la norma de normas. Entre otros, las nociones de igualdad, diferenciación, educación, derechos humanos, libre expresión y desarrollo público y privado del hombre son herencias del cosmopolitismo. Aunque toda la Constitución bebe de ideales cosmopolitas, es clave que los principios y derechos fundamentales se vean influenciados de manera explícita y conformen la base para las demás construcciones de derechos sociales, económicos, culturales, colectivos y ambientales. Por eso la Tabla 2 permite dar un rápido vistazo de las influencias manifiestas en el texto mayor del Estado Social de Derecho: 
Tabla 2. Algunos principios y derechos fundamentales de la Constitución con ideas cosmopolitas

\begin{tabular}{lll}
\hline Idea & Artículo & \multicolumn{1}{c}{ Extracto del Artículo } \\
\hline 7 & $\begin{array}{l}\text { El Estado reconoce y protege la diversidad étnica y cultural de } \\
\text { la nación colombiana. }\end{array}$ \\
\cline { 2 - 3 } Igualdad & $\begin{array}{l}\text { Todas las personas nacen libres e iguales ante la ley, recibirán } \\
\text { la misma protección y trato de las autoridades y gozarán de } \\
\text { los mismos derechos, libertades y oportunidades sin ninguna } \\
\text { discriminación por razones de sexo, raza, origen nacional o } \\
\text { familiar, lengua, religión, opinión política o filosófica. }\end{array}$ \\
\hline
\end{tabular}

Diferenciación

27 El Estado garantiza las libertades de enseñanza, aprendizaje, investigación y cátedra.

Derechos

humanos

El Estado reconoce, sin discriminación alguna, la primacía de los derechos inalienables de la persona y ampara a la familia como institución básica de la sociedad.

15 Todas las personas tienen derecho a su intimidad personal y familiar y a su buen nombre, y el Estado debe respetarlos y

Desarrollo

privado

16 Todas las personas tienen derecho al libre desarrollo de su personalidad sin más limitaciones que las que imponen los derechos de los demás y el orden jurídico.

37 Toda parte del pueblo puede reunirse y manifestarse pública y pacíficamente. Sólo la ley podrá establecer de manera expresa los casos en los cuales se podrá limitar el ejercicio de este derecho.

Desarrollo

público
38 Se garantiza el derecho de libre asociación para el desarrollo de las distintas actividades que las personas realizan en sociedad.

39 Los trabajadores y empleadores tienen derecho a constituir sindicatos o asociaciones, sin intervención del Estado. Su reconocimiento jurídico se producirá con la simple inscripción del acta de constitución. 
Se garantiza la libertad de conciencia. Nadie será molestado por razón de sus convicciones o creencias ni compelido a revelarlas ni obligado a actuar contra su conciencia. a profesar libremente su religión y a difundirla en forma

Libre expresión individual o colectiva. Todas las confesiones religiosas e iglesias son igualmente libres ante la ley. su pensamiento y opiniones, la de informar y recibir información veraz e imparcial, y la de fundar medios de comunicación masiva.

Fuente: elaboración propia a partir de la Constitución Política de Colombia de 1991.

La anterior selección no significa que arbitrariamente se ignoran otros importantes aportes del cosmopolitismo en el texto constitucional. Sino que las fundaciones de la Carta Magna presentan suficientes indicios de cosmopolitismo en estas ideas para inculcar nuevos valores liberales y así transformar a Colombia. Citando a Judith Shklar (como se citó en Rorty, 1991), "una persona que cree que la crueldad es la peor cosa que se puede hacer" (p. 164). Esto es, efectivamente, un liberal. Y la Constitución es explícita en el artículo doceavo a la hora de repudiar actos que atenten contra la vida, la desaparición forzada, las torturas y los tratos o penas crueles, inhumanos o degradantes (República de Colombia, 1991). De la misma manera, el artículo 95 reza como deber de todo ciudadano colombiano "defender y difundir los derechos humanos como fundamento de la convivencia pacífica” (República de Colombia, 1991).

Definitivamente, la cultura de los derechos humanos es una cultura de carácter liberal. Además, la educación de generaciones como mecanismo de propagación de las ideas liberales parece más factible, siempre y cuando no se enseñe a definir como irracionales a los demás (Rorty, 1998). Al respecto, la Constitución de 1991 es rica en proteger la igualdad, por ejemplo: con el establecimiento de un sistema multipartidista (Alcántara e Ibeas, 2001); y conservar las diferencias con políticas de etnoeducación (Coral, Achicanoy, Delgado y Melo, 2007). Fortaleciendo la idea de cosmopolitismo en la Carta Magna, ésta también nos habla de la condición humana desde la esfera pública y privada como Hannah Arendt concibió. Al modo de ver de ella "el nacimiento de la ciudad-estado significó que el hombre recibía 'además de su vida privada, una especie de segunda vida, su bios politikos'” (Arendt, 1974, p. 41). Y aunque las formas estatales hayan superado hace mucho tiempo al Estado-nación, la constitución del Estado social de derecho no lo dejó por implícito, y permite la libre asociación y expresión que eventualmente tiene efectos en la esfera pública. Esto significa que su carácter cosmopolita la llevó al privilegio de un valor: la privacidad. 
En nuestro caso, el pluralismo como expresión de la igualdad y la privacidad, que entiende el consenso como pacto estratégico, se busca por mecanismos formales de ley que protegen todas las esferas del desarrollo humano. Aunque las políticas implementadas pueden reforzar el papel de las etnias desde la jurisprudencia (Parra y Herrera, 2005), no todos los grupos humanos pueden estar en acuerdo con dichas formas de ley. En otras palabras, los lineamientos definidos parecen referirse a comportamientos, valores y costumbres socialmente aceptadas para la convivencia pacífica dentro del Estado, o como algunos llamarían "contrato social". Pero el establecimiento de normas máximas puede ir en contra de la ética al tratar de reformar la identidad ciudadana a favor de la cohesión nacional y por supuesto, la supervivencia de las instituciones del Estado.

De acuerdo con Cortina (2005b), "la ética tiene, pues, por objeto el deber referido a las acciones buenas que se expresa en los juicios denominados 'morales'” (p. 62). Pero si esta tarea se le traslada a la política, nos podemos enfrentar a serios conflictos al no poder cobijar a todos los grupos humanos de la nación. En el privilegio de algunos valores, ¿está la Constitución imponiendo ciertos comportamientos, costumbres, valores y normas? ¿Fue esto un simple problema conceptual o es un proceso planificado de aculturación?

\section{¿Una posible aculturación para definir la visión de una nación?}

Las diferencias conceptuales, y más que conceptuales, esenciales de los grupos humanos nos recuerdan la idea de Gadamer (2007), en cuanto a que "toda vivencia implica horizontes anteriores y posteriores y se funde en última instancia con el continuum de las vivencias presentes de antes y después, en la unidad de corriente vivencial” (p. 308). En otras palabras, las corrientes de cosmopolitismo tienen impresas visiones filosóficas típicas del entorno occidental europeo que en muchos casos omite otras perspectivas, por nombrar un ejemplo, orientales.

En cuanto al pensamiento oriental, los problemas de los valores y, específicamente, del comportamiento humano fueron introducidos por medio de textos religiosos o compendios de lecciones filosóficas como los Vedas, los Upanishads, el Mahābhārata, el Tao Te Ching, los Analectas, entre otros. En general, recogen las enseñanzas de los diferentes líderes que transmitían sus ideas directamente a sus discípulos. Sobre estos textos, tiene sentido afirmar que el pensamiento oriental representa el triunfo de las ideas de Confucio (Bauer, 2009), así como el occidental las de Aristóteles ${ }^{9}$. Sin embargo, existen otras construcciones éticas complejas como las hindúes que conforman un sistema triangular de ética social, ética psicológica y filosofía de lo absoluto que se basa en la voluntad, la consciencia, el espectro de las acciones, las virtudes y elementos

\footnotetext{
${ }^{9}$ Onfray (2007) en su obra Las sabidurías de la antigüedad. Contrahistoria de la filosofía I, hace un interesante estudio histórico de las corrientes no tradicionales de desarrollo filosófico, destacando entre otras, el pensamiento oriental.
} 
psicológicos que se enseñan por medio de tareas a las cuales se deben adscribir cada clase social o etapa de disciplina espiritual (Kumar, 1925) ${ }^{10}$.

Algunos autores occidentales podrían calificar el pensamiento ético oriental como relativista y subjetivista, lo cual es una visión plagada de etnocentrismo y problemas metodológicos al buscar una ética comparada (Keown, 2005). Sin embargo, la realidad es que las diferentes visiones del mundo desequilibran nuestro modo de actuar (Panikkar, 2006), mucho más allá de lo que la hermenéutica puede descifrar o metodológicamente hacer cognoscible puesto que refiere a la más profunda esencia de la construcción del ser humano. ¿Serán estas construcciones del ser humano obstáculos para la construcción del Estado? ¿Fue el liberalismo, como posible expresión de cosmopolitismo, una influencia favorable en la Constitución Política de 1991?

Ofrecer un juicio sobre la favorabilidad del cosmopolitismo, por medios racionales, sería algo arriesgado a escasos 20 años de promulgar la Carta Magna, pero una reflexión sobre los ideales que ingresaron nos permite sugerir acerca de un proceso de aculturación. De acuerdo con Lewis (1985), esta se define como "proceso de transmisión cultural por contacto entre grupos con diferentes culturas, teniendo uno de ellos, generalmente, una civilización más altamente desarrollada”"11 (p. 153). García (2007), en el Diccionario de Relaciones Interculturales, la define como "la pérdida o transformación de algunos aspectos culturales en situaciones de contacto entre culturas” (p. 5). Este proceso, según Lerma (2006), es natural a las dinámicas culturales, se define por agentes activos que se resisten o permiten la transmisión y se da en diferentes tamaños de grupos humanos, resultando en casos extremos en 'deculturación'. Indica Leander (1989), que la aculturación puede clasificarse en tres tipologías: 1) espontánea, por contactos temporales sin relaciones de dominación entre culturas; 2) forzada, donde un poder para todos los grupos por igual define los patrones y velocidad de transmisión; y 3) obligada, que impone hechos, pero no velocidades de transmisión también en un contacto permanente.

En realidad, el inconveniente de la aculturación es que causa contracciones entre los grupos humanos. Para nuestro problema, si a la 'aculturación forzada' le agregamos el concepto de 'aculturación planificada', en la cual se incluyen los programas de desarrollo (Bastide, 1972), la entrada en vigor de la Constitución de 1991 y sus sucesivas reformas institucionales, fueron en efecto, aculturación y por ende fuente de conflictos. ¿Estábamos preparados para un liberalismo social?, ¿los valores cosmopolitas en las nociones de igualdad, diferenciación, educación, derechos humanos, libre expresión y desarrollo público y privado del hombre, respondían a las necesidades de nuestra cultura? ¿Los procesos de desarrollo implantados

\footnotetext{
${ }^{10}$ Entre otros aspectos sería interesante rastrear los triunfos ideológicos en cada Constitución de Colombia para construir una línea de tiempo que permita explicar diferentes fenómenos de transformación social y aculturación que originan dificultades o facilidades para el desarrollo colombiano.

${ }^{11}$ Lerma (2006) aclara que en psicología en el sentido que en antropología se da al proceso de enculturación, en sociología, socialización, y en pedagogía, educación y condicionamiento.
} 
funcionaron como se esperaba, o los inconvenientes fueron producto del argumento central de esta sección?

El siglo XXI trae la necesidad de orientar el pensamiento colombiano como una corriente capaz de transformar la realidad, instituir cambios oportunos e interactuar con la comunidad académica internacional para profundizar en los baldíos del saber. Sea que nuestras instituciones estén definidas por procesos de aculturación, y que estos hayan sido favorables o desfavorables, los retos de gestión intercultural generados para el Estado, la sociedad y la empresa, deben ser afrontados con la mayor responsabilidad (Bustamante y Aguilar, 2012). Kung (1999) precisa que no es posible un desarrollo económico y político sin pautas éticas que propicien su aceptación. Y los mundos de producción también se vieron perturbados por las políticas liberales de apertura, que afectan elementos de la cultura (Bustamante, Arboleda y Gutiérrez, 2010). Los problemas de este centenario serán más complejos que los de 1900.

Entre otros, se advierten problemas relacionados con la consolidación de la identidad nacional, la conservación del medio ambiente, el tratamiento del narcotráfico, los planes de actualización en infraestructura, las relaciones internacionales y el fomento y control de la inversión extranjera directa. Por otro lado, se mantienen varias constantes: el crecimiento económico, la educación en todo nivel, la desigualdad social, los sistemas políticos multipartidistas y el acceso a la salud. Todo esto y más se advierte en el acervo intelectual y problemático de Colombia.

\section{Conclusiones}

Este documento tuvo como propósito elevar un debate alrededor de los derechos y principios fundamentales de la Constitución Política de Colombia de 1991 contrastando desde el cosmopolitismo la posibilidad de un proceso de aculturación. El primer apartado presentó cómo el concepto de cosmopolitismo tiene aspiraciones universalistas, pero genera un problema en el reconocimiento de las particularidades cívicas, culturales y religiosas de los diversos grupos humanos. El segundo punto describió cómo Colombia fue esencialmente un país que se fundamentó en el poder manifiesto en la ley por parte de diferentes grupos nacionalistas y regionalistas. Luego, el tercer punto expuso los elementos de cosmopolitismo que permearon la Carta Magna de 1991. Finalmente, se presentó un debate sobre aculturación.

Al respecto debo anotar que los procesos vividos en Colombia no parecen ser resultado de aculturación, sino un clásico caso de construcción social de la realidad (Berger y Luckmann, 2001) atropellada, desordenada, inefectiva, polémica, pero reconocible dentro de una construcción social en el marco de la globalización. Aunque Colombia no presenta diferencias culturales, cívicas o religiosas tremendamente marcadas, sí exhibe dificultades de gobernabilidad. Además, se enfrenta a procesos globales que invitan a varios debates que van más allá del alcance de este artículo. 
Uno de los debates pendientes nos remite al problema de fundamentación cosmopolita de la legislación colombiana, desde una aproximación del derecho. Otra deuda que deja el documento sería el análisis de cada Constitución del país desde el cosmopolitismo para indagar por una posible tendencia y comparar con la introducción de diversas corrientes de pensamiento alrededor del mundo. También es interesante indagar por otras construcciones sociojurídicas que tengan bases en el cosmopolitismo, dígase códigos específicos, entidades o políticas públicas. Asimismo, otras investigaciones pueden complementar el estudio sobre aculturación en Colombia al cuestionar otros aparatos ideológicos del Estado o de sujeción social.

Finalmente, queda una duda mayor: a mi modo de ver, el cosmopolitismo no ha penetrado la mayoría de los debates en Colombia porque el país todavía no se encuentra en un estado avanzado de globalización. Los conflictos identitarios, étnicos y culturales son opacados por las dificultades de inequidad social y económica que han dado forma al conflicto colombiano por más de 50 años. Debo reconocer que es posible que el debate cosmopolita no sea de primera necesidad en el ámbito colombiano. Pero un país que no se adelante a sus necesidades, es un país que se arriesga a que los movimientos globales lo pongan en serios aprietos. Persiste la invitación para ampliar y fortalecer este debate desde todas las perspectivas.

\section{Referencias}

Alcántara, M. e Ibeas, J. (Eds.). (2001). Colombia ante los retos del siglo XXI: desarrollo, democracia y paz. Salamanca, España: Universidad de Salamanca.

Arendt, H. (1974). La condición humana. Barcelona, España: Editorial Seix Barral.

Bastide, R. (1972). Antropología aplicada. Buenos Aires, Argentina: Amorrortu.

Bauer, W. (2009). Historia de la Filosofía China. Barcelona, España: Herder.

Baumann, G. (2001). El enigma multicultural. Un replanteamiento de las identidades nacionales, étnicas y religiosas. Barcelona, España: Paidós.

Beck, U. (2006). Cosmopolitan vision. Cambridge, UK: Polity Press.

Berger, P. y Luckmann, T. (2001). La construcción social de la realidad. Buenos Aires, Argentina: Amorrortu editores.

Brinton, C. (1979). Historia de las ideas. En D. Sills (Ed.), Enciclopedia Internacional de las Ciencias Sociales (pp. 436-440). Madrid, España: Aguilar.

Bustamante, L. (2015). Cosmopolitismo y las barreras insalvables de la cultura y los gustos en La Ética Protestante y el Espíritu del Capitalismo de Max Weber. Revista Desafíos, 27 (1), 26-38. 
Bustamante, L. y Aguilar, S. (2012). Retos de gestión intercultural en las actividades de internacionalización de microempresas de Medellín. Revista Estudios Gerenciales, 29 (129), 456-465.

Bustamante, L., Arboleda, A. y Gutiérrez, J. (2010). Cultura, política industrial y competitividad internacional de PyMEs en Colombia. Revista Ad-Minister, 16, 83-98.

Cataño, G. (2005). La sociología en Colombia. Bogotá, Colombia: Plaza \& Janés.

Cataño, G. (2012). La introducción del pensamiento moderno en Colombia. Bogotá, Colombia: Universidad Externado de Colombia.

Coral, M., Achicanoy, M., Delgado, L. y Melo, J. (2007). La etnoeducación en la Constitución Política de 1991: base de la diversidad étnica y cultural de la nación. Bogotá, Colombia: Universidad Cooperativa de Colombia.

Cortina, A. (2005a). Ciudadanos del Mundo: Hacia una Teoría de la Ciudadanía. Madrid, España: Alianza Editorial.

Cortina, A. (2005b). Ética mínima. Introducción a la filosofía práctica. Madrid, España: Tecnos.

Eagleton, T. (1991). Ideology:An introduction. London: UK: Verso.

Gadamer, H. (2007). Verdad y Método. Salamanca, España: Ediciones Sígueme.

García, J. (2007). Aculturación. En A. Barañano, J. García, M. Cátedra y M. Devillard (Eds.), Diccionario de Relaciones Interculturales: Diversidad y Globalización (pp. 5-6). Madrid, España: Editorial Complutense.

Geertz, C. (1996). Los usos de la diversidad. Barcelona, España: Paidós.

Giddens, A., Bauman, Z., Luhmann, N. y Beck, U. (1996). Las consecuencias perversas de la modernidad. Modernidad, contingencia y riesgo. Barcelona, España: Anthropos.

Kant, I. (1998). Crítica de la razón pura: prólogo, traducción, notas e índices. Bogotá, Colombia: Alfaguara.

Keown, D. (2005). Buddhist Ethics. A Very Short Introduction. Oxford,UK: Oxford University Press.

Kumar, S. (1925). The Ethics of the Hindus. Calcutta, India: Calcutta University Press.

Kung, H. (1999). Una ética mundial para la economía y la política. Madrid, España: Tecnos.

Leander, B. (1989). Europa, Asia y África en América Latina y el Caribe: Migraciones "libres" en los siglos XIX y XX y sus efectos culturales. Ciudad de México, México: Siglo XXI.

Lerma, F. (2006). La cultura y sus procesos. Antropología cultural: guía para su estudio. Murcia, España: Ediciones Laborum. 
¿Cosmopolitismo o aculturación? Los principios y derechos fundamentales de la Constitución Política de Colombia de 1991

Lewis, J. (1985). Antropología simplificada. Ciudad de México, México: Selector.

Mannheim, K. (2004). Ideología y Utopía: Introducción a la Sociología del Conocimiento. Ciudad de México, México: Fondo de Cultura Económica.

Martínez, F. (2001). El Nacionalismo Cosmopolita. La referencia europea en la construcción nacional en Colombia, 1845-1900. Bogotá, Colombia: Banco de la República.

Mignolo, W. (2000). The Many Faces of Cosmo-polis: Border Thinking and Critical Cosmopolitanism. Public Culture, 12 (3), 721-749.

Ocampo, J. (2004). Constitución Política de Colombia. Reformas y sus actos legislativos. Bogotá, Colombia: Plaza \& Janés.

Olivé, L. (Comp.). (2004). Ética y diversidad cultural. Ciudad de México, México: Fondo de Cultura Económica.

Onfray, M. (2007). Las sabidurías de la antigüedad. Contrahistoria de la filosofía, I. Barcelona, España: Anagrama.

Panikkar, R. (2006). Paz e interculturalidad: una reflexión filosófica. Barcelona, España: Herder.

Parra, C. y Herrera, C. (2005). Cátedra viva intercultural: metodología. En C. Parra y G. Rodríguez (Eds.), Comunidades étnicas en Colombia: Cultura y Jurisprudencia (pp. 14-49). Bogotá, Colombia: Universidad del Rosario.

Reder, M. (2012). Globalización y filosofía. Barcelona, España: Herder.

República de Colombia. (1991). Constitución Política de Colombia. Recuperado de http://www.secretariasenado.gov.co/senado/basedoc/cp/constitucion_politica_1991.html

Rorty, R. (1991). Contingencia, ironía y solidaridad. Barcelona, España: Paidós.

Rorty, R. (1998). Derechos humanos, racionalidad y sentimentalidad. En S. Shute y S. Hurley (Eds.), De los derechos humanos (pp. 117-136). Madrid, España: Editorial Trotta.

Schmitt, C. (2002). El Nomos de la tierra en el derecho de gentes del "Ius Publicum Europaeum". Granada, España: Comares S.L.

Todorov, T. (1991). Nosotros y los otros: reflexión sobre la diversidad humana. Ciudad de México, México: Siglo XXI Editores.

Toulmin, S. (1992). Cosmopolis: The Hidden Agenda of Modernity. Chicago,IL: University of Chicago Press.

Weber, M. (2003). La ética protestante y el espíritu del capitalismo. Ciudad de México, México: Fondo de Cultura Económica. 